University of New Hampshire

University of New Hampshire Scholars' Repository

6-2007

\title{
Classification of adults with problematic internet experiences: Linking internet and conventional problems from a clinical perspective.
}

\author{
Kimberly J. Mitchell \\ University of New Hampshire - Main Campus \\ David Finkelhor \\ University of New Hampshire - Main Campus, David.Finkelhor@unh.edu \\ Kathryn Becker-Blease \\ Washington State University
}

Follow this and additional works at: https://scholars.unh.edu/psych_facpub

\section{Recommended Citation}

Mitchell, K.J., Finkelhor, D., Becker-Blease, K.A. Classification of adults with problematic internet experiences: Linking internet and conventional problems from a clinical perspective. (2007) Cyberpsychology and Behavior, 10 (3), pp. 381-392.

This Article is brought to you for free and open access by the College of Liberal Arts (COLA) at University of New Hampshire Scholars' Repository. It has been accepted for inclusion in Psychology Scholarship by an authorized administrator of University of New Hampshire Scholars' Repository. For more information, please contact Scholarly.Communication@unh.edu. 


\title{
Classification of Adults with Problematic Internet Experiences: Linking Internet and Conventional Problems from a Clinical Perspective
}

\author{
KIMBERLY J. MITCHELL, Ph.D., ${ }^{1}$ DAVID FINKELHOR, Ph.D., ${ }^{1}$ \\ and KATHRYN A. BECKER-BLEASE, Ph.D. ${ }^{2}$
}

\begin{abstract}
This article utilizes data from clinical reports of 929 adults to examine whether various problematic Internet experiences are distinctly different from or extensions of conventional problems. A TwoStep Cluster Analysis identified three mutually exclusive groups of adults, those with (1) online relationship problems and victimization; (2) online and offline problems; and (3) marital discord. Results suggest some initial support for the idea that problematic Internet experiences are often extensions of experiences and behaviors that pre-date the Internet. However, the Internet may be introducing some qualitatively new dimensions-such as an increased severity, an increased frequency, or unique dynamics-that require new responses or interventions.
\end{abstract}

\section{INTRODUCTION}

$\mathrm{C}$ LINICIANS ARE INCREASINGLY being called upon to impart advice concerning how the Internet is impacting mental health, along with strategies for preventing or intervening with problems that may result from online behaviors and experiences. Much of the information about Internet-related problems involves adults who use the Internet for various sexual exploits, such as use of legal and illegal pornography, ${ }^{1,2}$ and sexual activity or conversation ("cybersex"). ${ }^{3,4}$ Related to these online concerns, and typically studied in conjunction with them, are problems related to Internet addiction, 5,6 compulsive use of the Internet for particular online pursuits, ${ }^{7}$ and impulse control problems. ${ }^{8,9}$ Still, questions remain about the characteristics of adults who experience various problems on the Internet.
Adults receiving mental health services may quite likely be experiencing Internet-related problems for a number of reasons. First, it can readily be imagined that the Internet might create new opportunities for conflict and deviance among those with the kinds of problems typically seen by mental health clinicians. For example, a client experiencing marital conflict who would not have sought out a "real-life" affair may participate in cybersex with someone miles away. A person with a sexual attraction to children, too inhibited or afraid to purchase pornography from a store, might find it difficult to inhibit the desire to search for pornography while using a computer. Second, Internet use may intersect with other clients' vulnerabilities to produce new problems. For example, people with developmental disabilities may be vulnerable to new kinds of online scams and fraud. Mental health conditions such as obsessive-compulsive disorder may

${ }^{1}$ Crimes against Children Research Center, University of New Hampshire, Durham, New Hampshire.

${ }^{2}$ Department of Psychology, Washington State University at Vancouver, Vancouver, Washington. 
make it difficult for some clients to put limits on time spent online.

\section{Survey of Internet Mental Health Issues}

The Survey of Internet Mental Health Issues (SIMHI) was an exploratory study of the variety of problematic Internet experiences being seen by mental health professionals. Researchers and clinicians identified a wide variety of problematic Internet behaviors and experiences among adult and youth clients receiving mental health treatment. From this, we developed an 11-category inventory of problematic Internet experiences. These non-mutually exclusive problematic Internet experiences involved overuse of the Internet; pornography use; sexual exploitation and abuse; online infidelity; gaming, gambling, and fantasy role-playing; harassment; isolative-avoidant behavior; fraud, stealing or deception; failed online relationships; exposure to non-sexual harmful material; and risky or inappropriate use (not otherwise specified). ${ }^{10}$

Virtually all of these Internet problem behaviors are, to a greater or lesser extent, extensions of problem behaviors that pre-existed the advent of the Internet (e.g., pornography, over-involvement in certain activities, gambling). Have the Internet forms of the problem, however, added something qualitatively new? The new element could, for example, be (1) an increase in the severity of the problem; (2) an increase in its frequency; or (3) providing some unique dynamics that require new responses or interventions.

One problem for which the Internet component is generally thought to be more severe as well as more frequent is the problem of pornography exposure. For example, law enforcement officials believe that the Internet has made illegal pornography, such as images of children and other extreme kinds of images, more widely available to people. ${ }^{11}$ Although there are no concrete statistics, it appears likely that the Internet has made all forms of pornography more generally available than they were when they had to be purchased in person at commercial establishments.

An example of an older problem to which the Internet has added a new dynamic might be the case of online infidelity. It might be argued that the cybersex form of infidelity adds a somewhat new dynamic to the conventional forms of infidelity. Because traditional norms about marital and relationship fidelity are generally thought of in terms of unfaithful acts conducted in the presence of the third party, the status of the imaginary exchanges conducted electronically is ambiguous, and may pre- cipitate somewhat different kinds of conflicts as well as misunderstandings. In most cases, the lines are unclear between what is an old problem in a new medium, and what is a qualitatively new problem.

\section{Current goals}

In the current paper, we examine how this 11-category inventory of problematic Internet experiences pertains to adults. Inventory categories excluded from our analyses include sexual exploitation and abuse victimization; harassment perpetration; fraud, stealing or deception perpetration; exposure to non-sexual harmful material, and unwanted pornography exposure due to low endorsement by adult clients $(<4 \%$ of sample). We examine the remaining problematic Internet experiences to see whether they are distinctly different from, or extensions of the conventional problems seen by clinicians. Specifically, we aim to classify, with a clinical population, clusters of adults identified as having problematic Internet experiences based on these and other conventional problems presenting in treatment. First, we examine the differentiating patterns among a variety of problematic Internet experiences, mental and physical health problems, family or other relationship problems, work problems, victimization, and aggressive behavior coming to the attention of mental health professionals. Second, we examine the role of problematic Internet experiences on clients' reasons for treatment.

\section{METHODS}

\section{Procedure}

Preliminary postcard survey. A random sample of names and addresses were gathered from professional organization memberships lists predominantly in the areas of psychology, psychiatry, and social work. The final sample consisted of 31,382 professionals. Each professional received a cover letter in 2003 and a 1-page postage-paid survey on which respondents could indicate whether they had worked with any clients (child and/or adult) in the past 5 years who had various problematic Internet experiences, including those involving adult pornography; child pornography; sexual approaches, solicitations, or behavior; a romantic or sexual relationship; a close relationship or friendship; fraud or other scams; gaming or role-playing; racist or hate material; violent material; and aggressive behavior (e.g., harassment, stalking).

The process of completing and returning the mail 
survey was taken as assent to participate in this study. At the end of the postcard survey, respondents were asked whether they would like to participate in a more detailed follow-up survey about professional needs in this area and some anonymous information about one of their clients (if applicable). There were 7,841 valid respondents to the postcard survey (a 25\% response rate at the minimum given that our bulk-mailing procedures likely resulted in some respondents never receiving the mailing), of which $92 \%(n=7,232)$ had provided direct services to clients within the past 5 years. This study, and all its methodology were conducted in compliance with the University of New Hampshire's Institutional Review Board.

\section{Detailed survey}

Instrument. The follow-up instrument was designed through semi-structured interviews with a variety of mental health professionals. The survey covered several sections aimed at understanding the client's problematic Internet experience including client demographics and background, mental health service referral, primary and secondary problems the client was in treatment for (e.g., various issues surrounding mental and physical health, family and/or relationships, school and/or work, victimization, aggression, computer/Internet), characteristics of the Internet problem, and diagnosis and treatment. Professionals were asked to respond to this survey about one client only, and the following three rules applied for choosing one: (1) if you have encountered only one client with a problematic Internet experience, please complete this survey about that client, (2) if you have encountered more than one, please give us information about the most recent youth client (under 18), if you have youth clients, and (3) otherwise, please give us information about the adult client you have seen most recently. The survey was pre-tested on 100 professionals across all disciplines in the study.

Returns. A total of 3,398 respondents consented to participate in the Phase 2 follow-up survey (based on Phase 1 feedback). Of these, 2,170 returned a completed survey, resulting in a $64 \%$ response rate. Of these, $71 \%(n=1,534)$ encountered at least one client with a problematic Internet experience in the target time frame. Ninety-three cases were dropped from the current analysis because of duplication, difficulty in coding, or because the client was not the individual who had the problematic Internet experience, resulting in 1,441 cases. Of these, $64 \%$ ( $n=$ 929 ) were cases involving adults (18 years of age or older), which is the focus of the current paper. Demographic characteristics of the final 929 respondents and clients are provided in Tables 1 and 2, respectively.

\section{Measures and analyses}

A TwoStep Cluster Analysis, which we used to analyze our data, is an exploratory tool designed to reveal natural groupings (or clusters) within a data set that would otherwise not be apparent. ${ }^{12}$ This procedure has all the features of traditional clustering methods, with the added benefits of handling categorical and continuous variables, automatic selection of number of clusters, scalability, and use with large datasets.

Variables in this procedure included the occurrence of problematic Internet experiences and other conventional problems presenting in treatment. These were all dichotomous variables (yes/no for each): (1) Problematic Internet Experiences-online infidelity, sexual exploitation or abuse perpetration; harassment victimization; fraud, stealing or deception victimization; overuse; gaming or role-playing; pornography use; isolative-avoidant use; risky or inappropriate use, not otherwise specified, failed online relationships; and computer or Internet addiction (computer or Internet addiction was identified based on a single yes/no item and is not meant to represent a diagnosis of Internet addiction that requires a full assessment); (2) Mental and Physical Health Problems-somatic complaints or insomnia, anxiety and/or phobias, diagnosed mental illness, suicidal ideation or attempt, grief, physical disability or chronic health problem, drug or alcohol problems, and a specific life stressor; (3) Family and/or Other Relationship Problems-social withdrawal, marital conflict or divorce, parent-child conflict, some other relationship problem, substance abuse problems within family, disciplinary problems at home, trouble making friends, and problems at work); (4) Victimization-physical, sexual, bullying, emotional; and (5) Aggressive Behavior-aggressive acting out or conduct problems, bullying behavior, sexual acting out, sexual abuse to others, criminal history.

\section{RESULTS}

\section{Classification of adults with problematic Internet experiences}

Adults were clustered using the log-likelihood distance measure. Schwartz's Bayesian Criterion 
Table 1. Demographic Characteristics of Respondents with Adult Clients

\begin{tabular}{|c|c|c|}
\hline \multirow[b]{2}{*}{ Demographic characteristic } & \multicolumn{2}{|c|}{ All respondents $(n=929)$} \\
\hline & $n$ & $\begin{array}{l}\text { Prevalence } \\
\quad(\%)\end{array}$ \\
\hline \multicolumn{3}{|l|}{ Gender } \\
\hline Female & 546 & 59 \\
\hline Male & 382 & 41 \\
\hline Not ascertainable & 1 & $<1$ \\
\hline \multicolumn{3}{|l|}{ Age } \\
\hline 30 years or younger & 11 & 1 \\
\hline $31-40$ years old & 95 & 10 \\
\hline $41-50$ years old & 225 & 24 \\
\hline Over 50 years old & 587 & 63 \\
\hline Not ascertainable & 11 & 1 \\
\hline \multicolumn{3}{|l|}{ Race/ethnicity ${ }^{a}$} \\
\hline European-American & 877 & 94 \\
\hline Asian or Pacific Islander & 18 & 2 \\
\hline Hispanic or Latino & 16 & 2 \\
\hline African-American & 7 & 1 \\
\hline Native American or Alaskan Native & 6 & 1 \\
\hline Other & 2 & $<1$ \\
\hline Not ascertainable & 14 & 1 \\
\hline \multicolumn{3}{|l|}{ Highest earned degree } \\
\hline Bachelor's & 4 & $<1$ \\
\hline Master's & 351 & 38 \\
\hline Ph.D. & 416 & 45 \\
\hline M.D. & 59 & 6 \\
\hline Psy.D. & 62 & 7 \\
\hline Ed.D. & 25 & 3 \\
\hline Other (C.A.S., D.Min., D.O., Ed.S.) & 8 & 1 \\
\hline Not ascertainable & 4 & $<1$ \\
\hline \multicolumn{3}{|l|}{ Primary profession } \\
\hline Psychologist & 445 & 48 \\
\hline Social worker & 213 & 23 \\
\hline Marriage and/or family therapist & 99 & 11 \\
\hline Mental health counselor & 68 & 7 \\
\hline Psychiatrist & 60 & 7 \\
\hline School counselor & 6 & 1 \\
\hline School psychologist & 9 & 1 \\
\hline Other (clergy, professor, EAP, etc.) & 29 & 3 \\
\hline \multicolumn{3}{|l|}{$\begin{array}{l}\text { Number of years providing direct } \\
\text { services to clients }\end{array}$} \\
\hline Less than 1 year & 0 & 0 \\
\hline More than 1 year to 5 years & 22 & 2 \\
\hline More than 5 years to 10 years & 91 & 10 \\
\hline More than 10 years to 15 years & 157 & 17 \\
\hline More than 15 years to 20 years & 141 & 15 \\
\hline More than 20 years & 509 & 55 \\
\hline Not ascertainable & 9 & 1 \\
\hline \multicolumn{3}{|l|}{ Employment setting ${ }^{\mathrm{a}}$} \\
\hline Independent practice & 587 & 63 \\
\hline Mental health clinic & 102 & 11 \\
\hline School or other educational setting & 23 & 3 \\
\hline University & 73 & 8 \\
\hline
\end{tabular}


Table 1. Demographic Characteristics of Respondents with Adult Clients $\left(\right.$ CONT'D $^{\prime}$

\begin{tabular}{lrr}
\hline & All respondents $(n=929)$ \\
\cline { 2 - 3 } Demographic characteristic & \multicolumn{1}{c}{$n$} & $\begin{array}{c}\text { Prevalence } \\
(\%)\end{array}$ \\
\hline Medical hospital & 32 & 3 \\
Psychiatric hospital & 27 & 3 \\
Court system & 7 & 1 \\
Child advocacy center & 1 & $<1$ \\
Corrections (prison, jail, probation, parole) & 20 & 2 \\
Residential treatment facility or group home & 7 & 1 \\
Other (church, social service agency, etc.) & 89 & 10 \\
Not ascertainable & 8 & 1 \\
Type of area served & & \\
Suburban & 395 & 43 \\
Urban & 391 & 42 \\
Rural & 155 & 17 \\
Not ascertainable & 14 & 1 \\
\hline
\end{tabular}

aMultiple responses possible.

Note: Numbers that do not add to $100 \%$ are due to rounding unless otherwise indicated.

(BIC) was used as the clustering criterion. The number of clusters was determined as part of the analysis procedure (and not predetermined by the authors), resulting in three mutually exclusive groups of adults: cluster 1 , online relationship problems and victimization $(28 \%)$; cluster 2 , online and offline problems (29\%); and cluster 3, marital discord $(43 \%)$. To examine the reliability of the cluster solution, the sample was randomly divided into 2 groups of adults and a cluster analysis was performed on each half. The results of each cluster analysis, including the proportion and structure of clusters, were similar to the original solution and to each other. These results suggest the three-cluster solution is robust and not an artifact of the clustering technique.

Cluster profiles are provided in Table 3 and show the percentage of adults with various problematic Internet experiences and conventional problems presenting in treatment, across clusters. To reduce Type I errors, $\alpha$ was set at $p \leq 0.01$. Based on the dichotomous nature of the variables, there were certain problems that contributed significantly to a cluster because of either high or low occurrence, compared to other clusters. Those problems that contributed to the cluster development due to their high occurrence are in bold text in the tables and those that contributed due to their low occurrence are italicized for ease of identification.
Cluster 1: Online relationship problems and victimization ( $n=261,28 \%$ of the sample)

Problematic Internet experiences. Adults in this group were characterized by significantly higher rates of harassment victimization; fraud, stealing or deception victimization; failed online relationships; and risky or inappropriate use, not otherwise specified than most other adults in this clinical sample (Table 3). In contrast, the adults in this group had significantly low rates of online infidelity; overuse; gaming, gambling or role-playing; pornography use; and computer or Internet addiction.

Conventional problems. These adults were also characterized by high rates of conventional problems involving some other relationship problem (i.e., non-familial) and emotional victimization (Table 3). They had low rates of a specific life stressor, marital conflict or divorce, problems at work, bullying others, and sexual acting out.

Role of Internet problem in treatment. The Internet problems experienced by adults in this cluster were categorized as a primary presenting problem for $57 \%$ of adults. For $34 \%$ of these adults, the Internet problem ultimately played a primary role in the client's reason for treatment; for $34 \%$ a secondary role, and for $32 \%$ the Internet problem was peripheral to other presenting problems. 
Table 2. Demographic Characteristics of Adult Clients Identified as Having a Problematic Internet Experience

\begin{tabular}{|c|c|c|}
\hline \multirow[b]{2}{*}{ Demographic characteristic } & \multicolumn{2}{|c|}{ Adult clients $(n=929)$} \\
\hline & $n$ & $\begin{array}{c}\text { Prevalence } \\
(\%)\end{array}$ \\
\hline \multicolumn{3}{|l|}{ Gender } \\
\hline Female & 285 & 31 \\
\hline Male & 644 & 69 \\
\hline \multicolumn{3}{|l|}{ Age when experience began } \\
\hline $13-17$ years old & 5 & 1 \\
\hline $18-30$ years old & 287 & 31 \\
\hline $31-40$ years old & 371 & 40 \\
\hline $41-50$ years old & 190 & 20 \\
\hline Over 50 years old & 52 & 5 \\
\hline Not ascertainable & 24 & 3 \\
\hline \multicolumn{3}{|l|}{ Marital status } \\
\hline Single, never married & 218 & 23 \\
\hline Married & 522 & 56 \\
\hline Separated & 38 & 4 \\
\hline Living with a partner & 30 & 3 \\
\hline Divorced & 112 & 12 \\
\hline Widowed & 9 & 1 \\
\hline \multicolumn{3}{|l|}{ Living status ${ }^{a}$} \\
\hline Alone & 185 & 19 \\
\hline With spouse or partner & 600 & 65 \\
\hline With own children & 237 & 25 \\
\hline Don't know & 3 & $<1$ \\
\hline \multicolumn{3}{|l|}{ Race/ethnicity ${ }^{\mathrm{a}}$} \\
\hline European-American & 857 & 92 \\
\hline Asian or Pacific Islander & 13 & 1 \\
\hline Hispanic or Latino & 33 & 3 \\
\hline African-American & 21 & 2 \\
\hline Native American or Alaskan Native & 9 & 1 \\
\hline Other & 2 & $<1$ \\
\hline Don't know/not ascertainable & 4 & $<1$ \\
\hline \multicolumn{3}{|l|}{ Annual household income } \\
\hline Less than $\$ 20,000$ & 125 & 13 \\
\hline Over $\$ 20,000$ to $\$ 50,000$ & 298 & 32 \\
\hline Over $\$ 50,000$ to $\$ 80,000$ & 213 & 23 \\
\hline Over $\$ 80,000$ & 164 & 18 \\
\hline Don't know/not ascertainable & 129 & 14 \\
\hline \multicolumn{3}{|l|}{ Employment status ${ }^{\mathrm{a}}$} \\
\hline Full-time & 589 & 63 \\
\hline In school & 93 & 10 \\
\hline Part-time & 108 & 12 \\
\hline Unemployed & 110 & 12 \\
\hline Retired & 15 & 2 \\
\hline Something else (e.g., disability) & 67 & 7 \\
\hline Not ascertainable & 2 & $<1$ \\
\hline
\end{tabular}

${ }^{a}$ Multiple responses possible.

Note: Numbers that do not add to $100 \%$ are due to rounding unless otherwise indicated. 


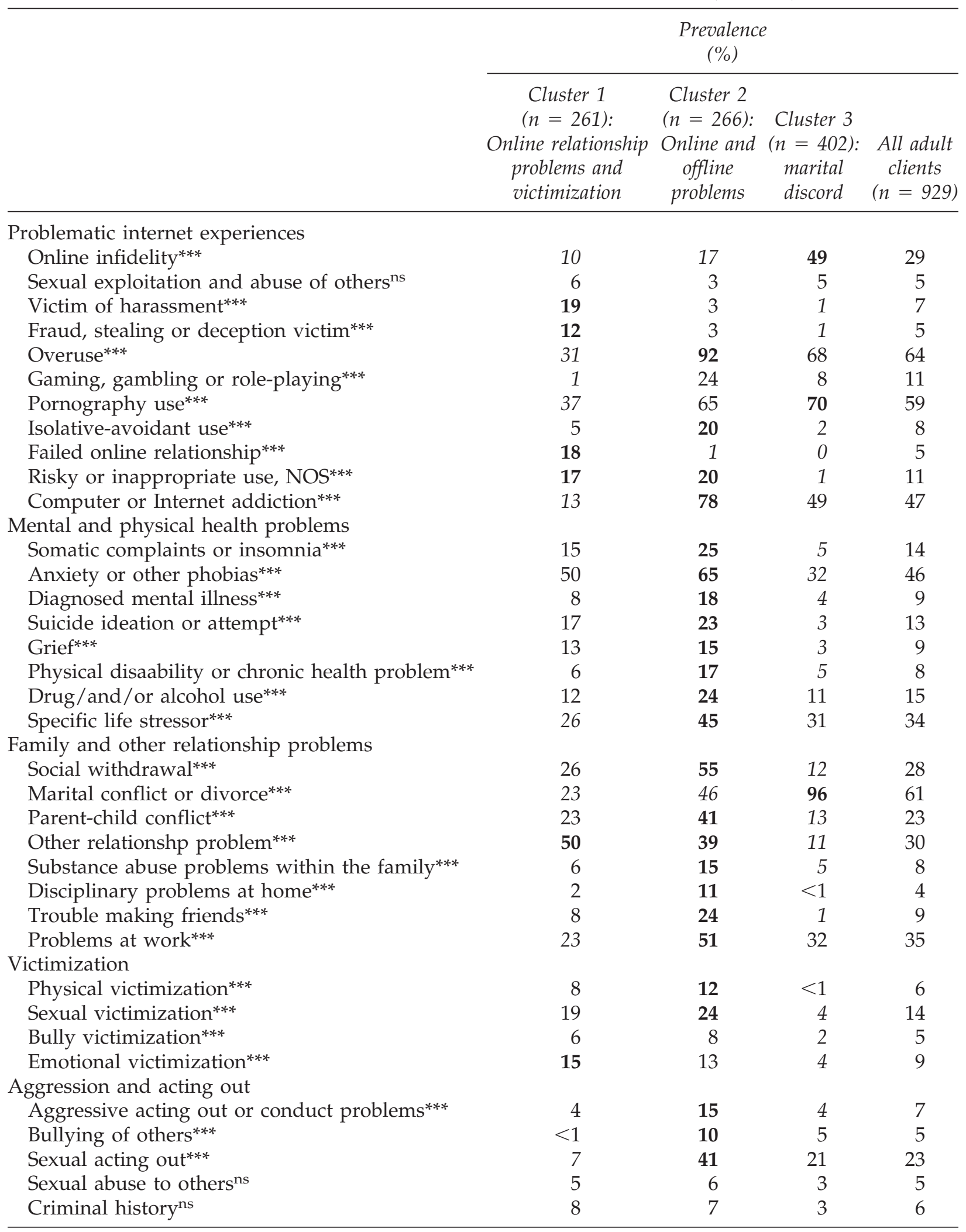

Bold cells reflect problems that significantly contributed to cluster formation due to their high occurrence. Italicized cells indicaate problems that significantly contributed to cluster development based on their low occurrence.

${ }^{* * *} p \leq 0.001$.

ns, not significant. 
Cluster 2: Online and offline problems $(n=266,29 \%$ of the sample)

Problematic Internet experiences. The adults included in the online and offline problems group were characterized by significantly higher rates of Internet overuse; gaming, gambling or role-playing; isolative-avoidant use; risky or inappropriate use, not otherwise specified; and computer or Internet addiction than most other adults in this clinical sample (Table 3). In contrast, the only Internet problem that contributed to this cluster development due to a low occurrence was online infidelity.

Conventional problems. Even more telling is the high rates of several conventional problems among this group including somatic complaints or insomnia, anxiety or other phobia, diagnosed mental illness, suicide ideation or attempt, grief, physical disability or chronic health problem, drug or alcohol use, a specific life stressor, social withdrawal, parent-child conflict, other relationship problem, substance abuse problems in the family, disciplinary problems at home, trouble making friends, problems at work, physical and sexual victimization, aggressive acting out or conduct problems, bullying others, and sexual acting out (Table 3 ). In contrast, the only conventional problem that contributed to this cluster development due to a low occurrence was marital conflict or divorce.

Role of Internet problem in treatment. The Internet problems experienced by adults in this cluster were categorized as a primary presenting problem for $43 \%$ of adults. For $32 \%$ of these adults, the Internet problem ultimately played a primary role in the client's reason for treatment; for $41 \%$ a secondary role, and for $26 \%$ the Internet problem was peripheral to other presenting problems.

Cluster 3: Marital discord ( $n=402,43 \%$

of the sample)

Problematic Internet experiences. Adults in the marital discord cluster were characterized by higher rates of online infidelity and pornography use than most other adults in this clinical sample (Table 3). In contrast, these adults had little to no Internet-related problems involving harassment victimization; fraud, stealing or deception victimization; isolativeavoidant use; failed online relationships; and risky or inappropriate use, NOS.

Conventional problems. The only conventional problem that was common for this group was problems related to marital conflict or divorce (Table 3).
They were commonly characterized by low rates of somatic complaints or insomnia; anxiety or other phobias; diagnosed mental illness; suicide ideation or attempt; grief; physical disability or chronic health problem; social withdrawal; parent-child conflict; other relationship problem; substance abuse problems in the family; disciplinary problems at home; trouble making friends; physical, sexual, bully and emotional victimization; and aggressive acting out or conduct problems.

Role of Internet problem in treatment. The Internet problems experienced by adults in this cluster were categorized as a primary presenting problem for $46 \%$ of adults. For $54 \%$ of these adults, the Internet problem ultimately played a primary role in the client's reason for treatment; for 33\% a secondary role, and for $13 \%$ the Internet problem was peripheral to other presenting problems.

\section{DISCUSSION}

This paper explored the relationship between a number of different problematic Internet experiences and conventional problems among a clinical sample of adults with Internet-related problems. We examined various problematic Internet experiences to see whether they were distinctly different from, or extensions of the conventional problems seen by clinicians. Findings suggest the existence of three mutually exclusive groups of adults, those involving (1) online relationship problems and victimization, (2) online and offline problems, and (3) marital discord.

\section{Online relationship problems and victimization}

Adults in this cluster were characterized by failed online relationships and online victimization, in the forms of harassment and fraud-related activities. Some were also engaging in behaviors that had the potential to place them at risk of harm or were considered inappropriate in nature. Likely related to these online problems, these adults also presented with conventional problems involving some non-familial relationship and emotional victimization. Some of the adults in this group developed Internet problems that stemmed from online relationships, behavior, or exchanges with other people not originally known to the client in person. There are certainly many benefits to meeting people online, and there are many successful stories of online relationships, but as we have seen, problems can occur as well. People with failed online relationships come 
into clinical work because of self-reported distress. These cases generally involved meeting people online, developing romances or emotional feelings, and finding that the other individual did not reciprocate those feelings, ended the relationship abruptly, was not who they portrayed themselves as, or engaged in abuse.

These adults did present with other conventional problems that contributed to the development of the cluster, such as a specific life stressor, marital conflict or divorce, and problems at work. But the distinguishing feature of these problems was their low occurrence compared to adults in the other two clusters. There were other conventional problems seen amongst the adults in this cluster but they did not contribute to cluster development.

\section{Online and offline problems}

We also identified a group of adults that could be described as having significant problems both online and offline. Their Internet problems involved overuse; gaming, gambling or role-playing; isolative-avoidant use; risky or inappropriate use, and computer or Internet addiction. Overuse of the Internet was a major problem for this group. Overuse involved excessive use, either in general or for specific types of behaviors, such as gaming that was also a problem for this group. A large research base is currently in development concerning people who use the Internet excessively and those who have apparently lost control of their behavior and actions. This research tends to focus on people who use the Internet for sexual reasons or to excess and they have been identified as exhibiting addiction-, compulsive-, and impulse control-related problems. $3,6-8,13,14$ Users who are considered addicted typically meet all the DSM-IV criteria for other addictions and criteria for assessment of both Internet and computer addiction and sexual addiction have been developed based on criteria for gambling addiction. ${ }^{15}$ Further research is needed to understand if Internet use is associated with rewards similar to those experienced by those addicted to substances or gambling, and if withdrawal from Internet use is analogous to other forms of addiction. There is also a need to address value judgments in determining if Internet use leads to adverse consequences, as DSM-IV criteria are based, in part, in continuing to use despite consequences. To some, pursuing online relationships to the exclusion of offline relationships or using the Internet to escape into a fantasy world is de facto evidence of negative consequences of Internet use. Other people view it as acceptable, and, in some cases adaptive, to choose to interact online rather than offline, especially for people who have difficulty with social interactions because of a mental or physical disability. ${ }^{16}$

Some of these adults were using the Internet to the point where they were isolating themselves from offline social interaction (isolative-avoidant use). This happened in two ways. Some adults chose to have all their social interactions online with little or no social interaction offline, whereas others spent so much time with online pursuits that they isolated themselves from family, friends, and social engagements. Little is known about online isolation. The sheer numbers of people who use the Internet make this a real candidate for problematic behavior, especially for those individuals with pre-existing issues of social isolation and phobia. It may be difficult clinically to distinguish between someone who would ordinarily be even more isolated were it not for their Internet activity, and people for whom their Internet activity is interfering with the potential for a fuller social life.

Some of the adults in this group were also engaged in behavior that was not exploitative or otherwise criminal, did not involve infidelity, and were not inherently problematic, but raised concerns due to their risky or inappropriate nature. These cases often involved sexual behavior and interaction with other individuals that began online and sometimes progressed into the real world. These behaviors became a problem when they engendered guilt feelings, or interfered with other activities, responsibilities or relationships. Some were clearly risky to one's health as in the case of adults using the Internet to meet other adults for casual and unprotected sex. Some of these cases may not have involved intrinsic risk, but became problems because of the value judgments of family, friends or therapists. Other situations were problematic due to the client's learning or mental deficiency-resulting in difficulty distinguishing between right and wrong, and identifying what was inappropriate, risky, or dangerous online.

Most notable for this group is the variety of conventional problems seen with these adults including various mental and physical health problems, family and other relationship problems, work problems, victimization, and aggression or sexually acting out. It is likely that, for many of these adults, their problematic Internet experiences were ancillary to these other problems. These adults may be particularly prone to problems online due to their vulnerability in other areas of their lives and clinicians should be aware of this potential. Given the diverse array of conventional problems, the Internet problems, for some adults, may be a mere extension of a broader problematic lifestyle. 


\section{Marital discord}

The most apparent problems seen with adults in this group were Internet infidelity and pornography use-and the associated marital conflict or divorce classically seen by mental health professionals (no notable problems in other domains were seen, in fact, these adults were marked by significantly lower occurrences of most other conventional problems examined). Exposure to Internet pornography becomes a problem when it engenders guilt feelings, or interferes with other activities, responsibilities or relationships. It appears to come into clinical work either from self-reported distress or because of interference with relationships. In particular, partner conflict over Internet pornography is sometimes connected to pornography overuse, but can exist even when pornography exposure is minimal.

Although infidelity is hardly new as a human or clinical problem, aspects of the Internet may have altered and complicated the issue. Online affairs are more easily hidden; contact does not involve an absence from home, the risk of being seen in public, or unaccounted expenses. ${ }^{17}$ Further, the Internet allows for instantaneous access to an almost unlimited choice of partners that would have been more difficult previously by persons in committed relationships. Even more important may be the coming into existence of new kinds of sexual and intimate exchanges, whose normative status is not clearly defined in many people's minds. Is it infidelity to have sexual conversations with strangers? To have sexualized conversations with others while pretending to be someone else? To access pornography? To engage in cybersex? A number of grey areas exist concerning what is online infidelity, though the ultimate decision depends on the individuals in the committed relationship.

\section{Role of the Internet}

The problematic Internet experiences identified in this study played different roles in the client's overall pattern of behaviors and treatment, depending on the cluster. For the majority of the adults in the online relationship problem and victimization cluster, a problematic Internet experience was a presenting problem when beginning treatment. For almost half of the adults in the other two clusters, a problematic Internet experience was a presenting problem. For clinicians treating adults who present with Internet problems, the relative importance of the Internet and its role in the client's greater behavior pattern is often clear. Yet, for other clinicians working with clients whose problematic Internet ex- periences do not initially present in treatment, the role of the Internet may still play a key function in the client's overall wellbeing and successful treatment. For example, for adults presenting with problems related to marital conflict, asking about Internet usage patterns and characteristics may prove beneficial in establishing a better understanding of the client's problems. As it turned out, Internet problems ultimately played a primary role in treatment decisions for a significant minority of adults in the online relationship problem and victimization; and the online and offline problem clusters. This was true for over half of the adults in the marital discord cluster. More often, treating Internet problems was secondary or peripheral to the other conventional problems adults presented in treatment with, at least for the online relationship problem and victimization cluster; and the online and offline problems cluster. For example, clinicians may primarily treat the problem of social withdrawal and address Internet usage and behaviors secondarily as a contributing factor.

The findings from this study provide some tentative support for the view that problematic Internet experiences are often extensions of experiences and behaviors that pre-date the Internet. Each of the identified clusters were defined by both online and offline problems. There were no clusters classified by online problems only, or offline problems only. This also suggests that online problems may manifest in ways similar to their conventional counterparts. Specifically, we identified adults with online problems related to victimization, marital conflict, and those with multiple problems across several domains of their lives. These are all problems clinicians have been encountering in their practice long before the advent of the Internet. For some, there may be no real distinction between the online and offline problems whereas for others, the Internet may have introduced something qualitatively new in the form of increase severity, increased frequency, or some unique dynamic that requires new responses or interventions. Clinicians may want to be alert for examples of how the Internet has changed problem behaviors and the dynamics of interpersonal conflict in significant ways.

\section{Clinical implications}

The findings from this study have some implications for mental health professionals working with the adult population. First, clinicians should ask questions about Internet use during assessment. Al- 
though it is unclear what proportion of professionals are encountering clients with problematic Internet experiences, the spectrum of experiences they are encountering is wide. Moreover the problems are varied in their presentation and ramifications. Professionals may not find out about these behaviors or understand their connections to other problems unless they inquire about them. Thus, professionals should be aware of the Internet and the potential problems people can encounter. They should be prepared to ask some basic screening questions during assessment to see if problematic Internet experiences are at all relevant to treatment for individual clients.

Second, professionals need to be aware of the potential signs that suggest their clients are having Internet-related problems. For example, adults in treatment with problems related to social withdrawal should be questioned about their Internet use, including how often they are online, when they are online, what they use the Internet for, and the degree of importance of the Internet in their lives. If the Internet seems to be a prominent component of their client's life, this may serve as a potential avenue for treatment that could alleviate some of the problems surrounding their social withdrawal. Similar signs exist for adults who present with marital conflict or emotional victimization. The role of the Internet, in terms of who they are communicating with online or what they are viewing online may play a key role in successful treatment.

Third, professionals should be aware of how problematic Internet experiences interact with conventional mental health issues. The Internet may be impacting several areas of their client's lives including relationships, family dynamics, divorce, step-families, sexual orientation, other mental health concerns, and work performance. For example, it might be argued that the cybersex form of infidelity adds a somewhat new dynamic to the conventional forms of infidelity. Because traditional norms about marital and relationship fidelity are generally thought of in terms of unfaithful acts conducted in the presence of the third party, the status of the imaginary exchanges conducted electronically is ambiguous, and may precipitate somewhat different kinds of conflicts as well as misunderstandings. Clinicians working with adults who are struggling in this area should be aware of the potential role people met online and other online material have played in their client's concerns, as well as the potential benefits of educational material and support groups available online.

\section{Limitations}

Although this study is a unique exploration into a new domain, a few limitations must be noted. First, the methodology was not designed to capture a representative sample of all mental health professionals, so the frequency with which problematic Internet experiences come to the attention of mental health professionals cannot be established from this study.

Second, the problematic Internet experiences in this study are not necessarily representative of all problematic experiences online (in terms of severity and characteristics of clients and cases) because many people with problems do not receive mental health services. It could be that some of the people most in need of mental health services due to problematic Internet experiences do not have access to mental health services. On the other end of the spectrum there are likely youth and adults who experience less severe or extreme unwanted or problematic experiences on the Internet that result in distress that goes unreported because those involved cope with them well without professional help. ${ }^{18}$ The long-term effects of these experiences are currently unknown but important to address in future research.

Third, professionals were only asked to respond about a single client, and although respondents were instructed on how to choose a client so cases would be as systematic as possible, it is conceivable that professionals decided to choose the more memorable, interesting or otherwise salient cases, possibly skewing cases in this way. Fourth, the study had a low response rate with the possibility that those who did not respond were those without cases or cases that would identify other types of Internet-related problems.

\section{CONCLUSION}

The findings from this article suggest the existence of three mutually exclusive groups of adults with problematic Internet experiences being seen in mental health settings, those with (1) online relationship problems and victimization; (2) online and offline problems; and (3) marital discord. We found some initial support for the idea that problematic Internet experiences are often extensions of experiences and behaviors that pre-date the Internet. However, the Internet may be introducing something qualitatively new to these conventional problems, such as an increased severity, increased fre- 
quency, or some unique dynamic that requires new responses or interventions. Clinicians should be aware of this possibility and be able to address the role the Internet may play in their adult client's overall well being.

\section{ACKNOWLEDGMENTS}

For the purposes of compliance with Section 507 of PL 104-208 (the "Stevens Amendment"), readers are advised that $100 \%$ of the funds for this program are derived from federal sources (Office of Juvenile Justice \& Delinquency Prevention). The total amount of federal funding involved is $\$ 267,738$. Points of view or opinions in this document are those of the authors and do not necessarily represent the official position or policies of the Department of Justice.

\section{REFERENCES}

1. Parker, T.S., \& Wampler, K.S. (2003). How bad is it? Perceptions of the relationship impact of different types of internet sexual activities. Contemporary Family Therapy 25:415-429.

2. Wolak, J., Mitchell, K.J., \& Finkelhor, D. (2003). Internet sex crimes against minors: the response of law enforcement. Alexandria, VA: National Center for Missing \& Exploited Children.

3. Cooper, A., Delmonico, D.L., \& Burg, R. (2000). Cybersex users, abusers, and compulsives: new findings and implications. Journal of Sexual Addiction \& Compulsivity 7:5-27.

4. Schneider, J.P. (2000). Effects of cybersex addiction on the family: results of a survey. Journal of Sexual Addiction $\mathcal{E}$ Compulsivity 7:31-58.

5. Pratarelli, M.E., \& Browne, B.L. (2002). Confirmatory factor analysis of Internet use and addiction. $\underline{C} y-$ berPsychology \& Behavior 5:53-64.

6. Young, K.S. (2004). Internet addiction. A new clinical phenomenon and its consequences. American Behavioral Scientist 48:402-415.

7. Cooper, A., Scherer, C.R., Boies, S.C., et al. (1999). Sexuality on the Internet: from sexual exploration to pathological expression. Professional Psychology: Research and Practice 30:154-164.

8. Shapira, N.A., Lessig, M.C., Goldsmith, T.D., et al. (2003). Problematic internet use: proposed classification and diagnostic criteria. Depression and Anxiety 17:207-216.

9. Treuer, T., Fabian, Z., \& Furedi, J. (2001). Internet addiction associated with features of impulse control disorder: is it a real psychiatric disorder? Journal of Affective Disorders 66:283.

10. Mitchell, K.J., Becker-Blease, K.A., \& Finkelhor, D. (2005). Inventory of problematic Internet experiences encountered in clinical practice. Professional Psychology: Research and Practice 36:498-509.

11. Jenkins, P. (2001). Beyond tolerance: child pornography online. New York: New York University Press.

12. SPSS Inc. (2005). Discover depth and flexibility with TwoStep cluster analysis. Available at: www.spss.com/ pdfs/S115AD8-1202A.pdf. Accessed February 16, 2005.

13. Carnes, P. (2001). Out of the shadows. Understanding sexual addiction, 3rd ed. Center City, MN: Hazelden.

14. Griffiths, M. (2001). Sex on the internet: observations and implications for internet sex addiction. [ournal of Sex Research 38:333-342.

15. Orzack, M.H., \& Ross, C.J. (2000). Should virtual sex be treated like other sex addictions? Journal of Sexual Addiction $\mathcal{E}$ Compulsivity 7:113-125.

16. Fox, S.A. (2000). The uses and abuses of computermediated communication for people with disabilities. In: Braithwaite, D.O., \& Thompson, T.L. (eds.), Handbook of communication and people with disabilities: research and application. Mahwah, NJ: Lawrence Erlbaum Associates, pp. 319-336.

17. Maheu, M.M., \& Subotnik, R.B. (2001). Infidelity on the Internet. Virtual relationships and real betrayal. Naperville, IL: Sourcebooks, Inc.

18. Finkelhor, D., Mitchell, K.J., \& Wolak, J. (2000). Online victimization: a report on the nation's youth. Alexandria, VA: National Center for Missing \& Exploited Children.

Address reprint requests to: Dr. Kimberly J. Mitchell Crimes against Children Research Center University of New Hampshire 10 West Edge Dr., Ste. 106 Durham, NH 03824

E-mail: Kimberly.Mitchell@unh.edu 


\section{This article has been cited by:}

1. Chia-Ching Chen, Tetsuji Yamada, John Smith. 2014. An Evaluation of Healthcare Information on the Internet: The Case of Colorectal Cancer Prevention. International Journal of Environmental Research and Public Health 11, 1058-1075. [CrossRef]

2. Abigail M. Judge, Fabian M. SalehSexting, Cybersex, and Internet Use: The Relationship Between Adolescent Sexual Behavior and Electronic Technologies 377-389. [CrossRef]

3. Shalini Misra, Daniel Stokols. 2012. A Typology of People-Environment Relationships in the Digital Age. Technology in Society - [CrossRef]

4. Kimberly J. Mitchell, Chiara Sabina, David Finkelhor, Melissa Wells. 2009. Index of Problematic Online Experiences: Item Characteristics and Correlation with Negative Symptomatology. CyberPsychology \& Bebavior 12:6, 707-711. [Abstract] [Full Text PDF] [Full Text PDF with Links]

5. Thomas P. Kalman. 2008. Clinical Encounters with Internet Pornography. Journal of the American Academy of Psychoanalysis and Dynamic Psychiatry 36, 593-618. [CrossRef] 